\title{
Study on the Effect of Leaders' Emotional Expressions on Followers' Performance-based on EASI
}

\author{
Rui Yang, Wei Li, Yan-juan Mo \\ Business school of Sichuan University, Chengdu, 610000, China \\ scuyangrui@163.com
}

\begin{abstract}
Leaders' emotions affect followers' task performance and peripheral performance, which is crucial to the organization's survival and success. However, the mechanisms for effect are not clear and the existing research results are quite different. Based on emotions as social information model, this paper discusses the followers' performance led by leaders' emotional expressions through affective reaction path and inferential path. These two paths may operate separately or in parallel and in any order. And followers' psychology maturities and familiarities with their leaders (in-group /out-group) play important role: When followers' psychology maturities and familiarities with their leaders are high(in-group), leaders' emotional expressions may affect followers' performance by providing relevant information about the situation (inferential path). When followers' psychology maturities and familiarities with their leaders are low (out-group), leaders' emotions can be directly transmitted to the followers through the emotional process and influence followers' impression of leaders' behaviors as well as their performance(affective reactions path).

Index Terms - leaders' emotional expressions; followers' performance; followers' psychology maturities; familiarities of followers and leader
\end{abstract}

\section{Introduction}

Leaders' emotional expressions have an enormous impact on followers in the communication and management process. Some scholars even point out that the leadership is essentially an emotional process (Volmer, 2012). Leaders show emotions and try to evoke the mood of their followers (Dasborough et al., 2009). Researches on the relationship between leaders' emotional expressions and their followers' performance, the existing results have big difference. Some studies show that positive emotional expressions can inspire and motivate followers to improve their job performance. George (2001) believes that leaders who express excitement, enthusiasm and optimism may be more likely to transfer efficacy, competition, optimistic and cheerful to their followers. Through positive emotions, leaders clearly express the vision of the organization, and draw the positive image of the future to promote the positive emotions of followers. Based on existing literature review, he finds that leaders' emotional expressions influence a series of followers' output, such as prosaically behaviors, organizational citizenship behaviors and team performance. Through a laboratory study, Sy (2005) finds that compared with negative ones, followers perform better with a positive emotional leader. In completing the task, they tend to cooperate with team members so as to spend less effort to achieve their goals; other studies have found that leaders' negative emotional expressions can also have some positive effect. For example, when leaders give their followers proper attribution and expectations, their anger to external groups can enhance group cohesion and followers' sense of identity, and thus stimulate motivation to external situation (Lewis, 2000). Victoria(2013) believes that both leaders' happiness and anger make contribution to followers' performance. It depends on whether the position pays more attention to innovation performance or the analysis performance: by influencing followers' emotional impact, leaders' emotional expressions exert an effect on followers' performance.

In order to improve the work performance, what should the leaders do, to express positive emotion or negative emotion? To solve this problem, based on the emotions as social information (Van Kleef, 2009), this study tries to establish a model, which explains how leaders' emotional expressions influence their followers' performance. Furthermore, this study attempts to explore which factors will affect the model mechanism from the perspective of their followers.

The article is organized as follows. First, we provide a literature review on relevant topics. Second, we investigate possible factors leading to the followers' performance in leaders' emotional expressions process from the perspective of followers and build leaders' emotion model. Third, we provide some management advice for leaders. Finally, we discuss the research contribution, deficiency, and direction for the future study.

\section{Literature Review}

\section{A. Leaders' Emotional Expressions}

For the concept of emotional expressions, there is no unified definition and distinction in the academic circles. Some scholars define it as emotional expressions; others define it as emotional display. Lewis (2000) defines emotional expressions as individual facial expressions can be observed from the change of the voice and movement. This change is the real response of individual's inner emotion (Topolinski, 2009). In this article, we divide leader's emotional expressions into two aspects: how (emotional expressions mechanism) and what (the types of emotional expressions) leaders express. Leaders show different types of emotional state and overt behaviors (mainly including facial expressions, tone, and their postures, etc.) so as to pass some kind of emotional information. The dimensions of emotional expressions have a variety of divisions. And the double-dimensional model gets a higher recognition in academia. For example, Kleef (2009) divides 
emotional expressions into positive (Happy as the main representative) and negative (Anger as the main representative). Brundin (2008) points out positive emotion expressions include self-confident and satisfaction, while negative emotion expressions include depression, anxiety, confusion and tension.

\section{B. Followers' Performance}

Along with economic development and the change of organization structure, "Task" as the core of performance appraisal research is challenged. Academia gradually extends the connotation of work performance. Borman and Motowidlo (1993) divide performance into task performance and contextual performance. Task performance is not only closely related to the concrete position of the work content, but the individual ability, to complete the task proficiency and working knowledge are also closely related. It mainly emphasizes proficiency and motivation to complete the task. Contextual performance is closely related to organizational characteristics and environmental factors. It includes interpersonal skills, good working relationships and motivation to help others to get the job done effectively. Kats and Kahn (1978) think these behaviors are very important to the longterm development of the organization. Because they can reduce the friction between departments and help departments coordinate with each other for completing organizational goals.

\section{Emotions as Social Information (EASI)}

Emotions as social information(As shown in figure 1) put forward by Van Kleef (2009) points out that the emotional expressions influence the behavior of the observer through inferential path and affective reactions path. Prediction of the two processes depends on the observer's information processing factors and social-relational factors.

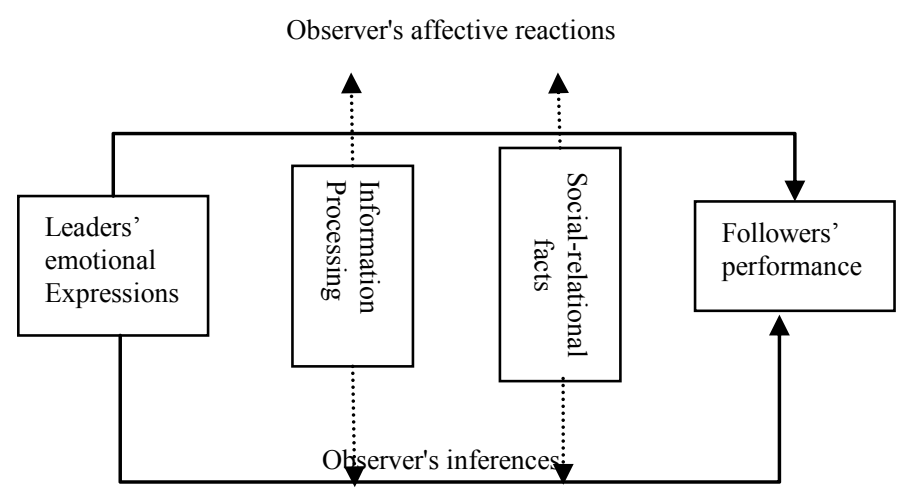

Figure 1 EASI: Van Kleef, G. A. (2009). How emotions regulate social life: The emotions as social information (EASI) model. Current Directions in Psychological Science, 18(3), 184-188.

Inferential path: Based on the emotions of others, the observer can infer the information such as their emotions, attitude and behavior intention that may adversely affect the behavior of the observer. When a person is the target of anger, he may therefore postulate that he did something wrong. This assumption may produce a series of actions (such as apology, change individual behaviors); While a person is the target of satisfaction, he might think things are going well (inference), then he will continue to keep this kind of behavior.

Affective reactions path: emotional expressions induce observer's affective reactions to influence their behavior. These emotional reactions mainly include two types. First of all, emotions can be directly transmitted to the recipient through the emotional process (Barsade, 2012); second, the emotional expression may influence receiver's impression of emotional behavior as well as relationships between emotional behavior and the recipient by passing social orientation and relationship (Weiss, 1996).

\section{Effect of Leaders' Emotional Expressions on Followers' Performance-A New Perspective}

To sum up, this article argues that the leaders' emotional expressions influence followers' performance through inferential path and affective reactions path. First, leaders' emotions can provoke affiliate corresponding emotional responses, by influencing the followers' emotional responses to motivate subordinates, and affect the subordinate's performance. Bono and Ilies (2006) think compared with the negative emotions; the leadership of positive emotions can arouse the enthusiasm of followers more, and improve their recognition of leadership. Stefanie and Johnson (2008) believe leaders' emotional expressions will mobilize the positive emotions of others through the emotional contagion mechanism. In this way, the leader's positive and optimistic mood will be subordinate by their followers, subsequently comes to a good result. The impact of negative emotions effect is just the opposite. The degree of followers' emotional contagion induced by emotional contagion mechanism is related to the degree of leaders' emotional expressions (Gooty et al., 2010). The stronger leaders express emotions, the more followers imitate, and the more intense emotional contagion will be.

Cognitive evaluation theory points out that when a person is the object of display of anger, he may conclude what he did wrong. This inference will then guide the behavior (Such as apology, change previous practice). When a person become happy mood display objects, he may infer that things are going well, which may keep his or her existing state of action. As emotional expression is a kind of work related information, leaders' emotional expressions guide followers' work attitudes and behaviors. Leader's negative emotional expression could herald an unqualified performance, which makes followers work harder (Sy, Côté, Saavedra, 2005).

The communication between leader and followers is a two-way interactive process. The existing research about the influence of leaders' emotional expressions on followers' performance are mostly from the perspective of leadership, such as leaders' emotional intelligence (Goleman, et, al, 2000 ; Wong , et ,al , 2002 ;Busso , 2003 ), leaders' emotional expressions strategy (Humphrey , 2006) and so on. But the effect of leaders' emotional expressions on followers' performance depends not only on leaders, but more on 
follower's internal characteristics. Thus, this article instigates two factors which influence the dual path effect of leaders' emotional expressions as follow:

The effect of leaders' emotional expressions on followers' output is ultimately determined by followers' actual behaviors. So it is necessary to account for followers' characteristics to understand how followers respond to leader's emotion. And followers' psychology maturities are one of the most important measures (Waller, et, al, 1989). Psychology maturities refer to the individual willingness and motivation to do something, mainly in the processing of interpersonal relationship (Paul, Blanchard, 1988). Followers with high psychology maturities are proactive and optimistic. Through a matching questionnaire research, Luo (2008) found partial matches of followers' maturities and leadership style is positively associated with performance. Existing research results also show that no matter what leadership attitudes and behavior, followers with high maturities generally have higher performance. This is because when leaders show their emotions, followers with high psychology maturities tend to choose inferential path and analyze the cause rationally. Followers with high psychology maturities are high in the aspect of work will. They tend to be more and capable of positive information processing for leader's emotions. They will feel more positive emotions, so more willing to work hard, and their work performance will naturally high; Followers with low psychology maturities are low in the aspect of work will and more likely for negative information processing for leader's emotions. When leaders show emotions especially the negative ones, which can be directly transmitted to the followers through the emotional process. At this point, effective reactions path plays the main role.

Circle phenomenon is very common in many organizations (Hollander, 1978). Due to the differences of member characteristics and membership, as well as time constraints, leaders will develop more intimate relationship with a few followers in the organization, while keep a certain distance with other followers, which leads to in-group and outgroup. Graen and Schiemann (1978) points out inner circle members will get more attention, support, and even power. In exchange, leaders will get followers' respect and trust. Therefore a high level of the bidirectional interaction effect is produced. In-group members are more easily to have values identification and internalization with leader. They are more inclined to positive emotional information processing and interpretation to their leaders' emotions (inferential path); Even though leaders show negative emotions, in-group members may conclude what they did wrong. This inference will then guide them to change previous practice, which contributes to task performance. When leader is not happy, they may as friends show their concern and figure out what happened and whether the leaders need help. These behaviors help promote peripheral performance (Bakker \& Xanthopoulou, 2009). Out-group members may be getting less attention. They will build a more formal power relation with their leader. The exchange relationship between each other is lack of a positive interaction force. Thus out-group members will unscramble leader's emotional information in a neutral or negative way (affective reactions path). Subsequently, followers conflicted emotions to some of leader's views. And then evolved into behavior, which causing poor performance.

The model of leader's emotional expression on followers' performance are shown in Figure 2.

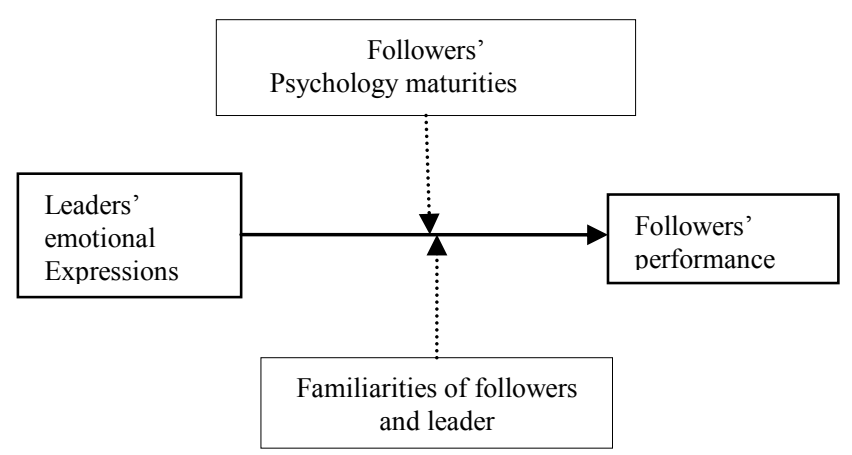

Figure 2 The model of leader's emotional expressions on followers' performance

\section{Management advice for leader}

\section{A. Express Proper Emotion}

Leaders' emotional expressions are task related information, which guide followers' work behaviors and attitudes. Leader's proper emotional expressions are conducive to the followers' emotional information processing degree, thus to promote the inference paths. Under normal circumstances, what emotion the leader expresses is consistent with what he passes. In the interactive process, leader's positive or negative emotional expressions are the external display of positive or negative emotional state. Leaders' emotional expressions are also feedback, which let followers know whether their behavior is right or wrong. Leaders show happiness when followers work well done. Followers will infer leader's satisfaction and approval information, thus increasing the confidence and enthusiasm for the work; Leaders can also show a certain degree of anger to transfer information that they are not satisfied with the followers' work behavior to make followers put in more effort to change their work behavior and improve the work performance.

\section{B. Improve the Subordinate Psychology Maturities to Increase the Followers' Positive Emotional Experience}

The higher followers' psychology maturities are, the more positive emotions they experience, the higher quality work they will do, and the better performance they will get. To make followers keep good working performance, leaders on the one hand should choose the appropriate emotional expression according to followers' maturities, on the other hand also should actively adopt some measures to improve the maturities of followers. Such as explicitly point out what skills should followers master, and strengthen the pertinence training. Intensify exercise on their non-intelligence is also necessary. Make them master basic emotion regulation methods so as to 
possess good psychological quality. Let followers feel organization's attention and concern on them.

\section{Show More Concern and Establish Good Relations with Followers}

Harmonious relationship between leaders and followers will direct leaders to show positive emotions which can bring positive emotion feelings. It is beneficial to establish a good interactive relationship and form a virtuous circle. Even though leaders' emotion expressions are negative, followers will also carry on the attribution and cognition, so as to reduce the influence of negative emotion. In daily management, therefore, leaders need to show more care behavior. And then there is some promoting effect on followers' work motivation and job satisfaction. Leaders should not be too much interference in the work of followers, continue to emphasize the task, otherwise it will let followers bound feeling, and then generate discontent. Leaders also eliminate diaphragm through close relationship with their followers. Effective leaders will try to blend in the followers' life other than work. Understand their motivation and meet their needs to raise performance.

\section{Conclusion}

Research on leaders' emotional expressions gradually cause extensive attention of scholars, which enables us to better recognize what leadership means, and how leaders improve followers' performance. Based on EASI, this article analyzes dual path effect of leaders' emotional expressions on followers' performance. To some extent explains why there are big differences of existing research from followers' perspectives: followers' maturities and familiarities with their leaders play decisive roles in the process of dual path effect. Despite the contributions of these studies, they are not without limitations. Firstly, this paper only analyzes two factors affecting the dual path effect from followers' perspectives. There will be many other factors. Thus further work might seek more factors that influence effect of leader's emotional expression on followers' performance from other perspectives. Additionally, this paper does not compare the applicable conditions of dual path in different situation. Which path plays the main role, inferential path or affective reactions path? Further research might take in-depth discussion in different situations. The emotion research in leadership field is more than the supplement to other studies. We should re-understand leadership from leadership perspective so as to make a new contribution to leadership theory.

\section{References}

[1] Bakker, A. B., \& Xanthopoulou, 2009, D. The crossover of daily work engagement: Test of an actor-partner inter-dependence model. Journal of Applied Psychology, 94, 1562-1571.

[2] Barsade, S. G. 2002. The ripple effect: Emotional contagion and its influence on group behavior. Administrative Science Quarterly, 47, 644-675.

[3] Borman W C, Motowidlo S J. 1993 .Expanding the criterion domain to include elements of contextual performance. In. Schmitt, N. Borman W.C. Personnel Selection in Organizations. San Francisco: Joss- Bass, 71-98.
[4] Bono,J.E,\& Ilies, R. 2006 , Charisma, positive emotions and mood contagion. The Leadership Quarterly, 17(4), 317-334.

[5] Busso, L. 2003.The Relationship between Emotional Intelligence and Contextual Performance: as Influence by Job Satisfaction and Locus of Control Orientation. Unpublished Doctoral Dissertation, Alliant International University,

[6] Dasborough, Marie T.; Ashkanasy, Neal M.; Tee, Eugene Y. J.; 2009. What goes around comes around: How memo-level negative emotional contagion can ultimately determine organizational attitudes toward leaders. Leadership Quarterly 20(4):571-585

[7] Goleman, D, Boyatzis, R, McKee, 2002.A.Primal Leadership: Realizing the Power of Emotional Intelligence. Boston: Harvard Business School Press.

[8] Gooty, J, Connelly, S, Griffith, J\& Gupta, 2010A. Leadership, affect and emotions: A state of the science review. The Leadership Quarterly,1 (6), 979-1004.

[9] Holloander,E ,P 1978. Leadership dynamics: A practical guide to effective relationships. New York: Free Press.

[10] Humphrey, R. H, 2006.Leading with emotional labor .paper presented at the Academy of Management Conference, Atlanta, GA.

[11] Katz, D, Kahn R L. 1978. The Social Psychology of Organization New York: Wiley, 131-134.

[12] Lewis K M. 2000, When Leaders Display Emotion: How Followers Respond to Negative Emotional Expression of Male and Female Leaders. Journal of Organizational Behavior 21(2):221-34.

[13] Luo Haibin, 2008, Study on relationship of leadership style, employee maturity, and employee performance. Market Modernization, 538(5):248.

[14] Paul Hersey. Kenneth Blanchard.1988.Management of Organizational Behavior: Utilizing Human Resource 4th ed. Englewood Cliffs, NJ.

[15] Sy T.Côté,S.\& Saavedra,R. 2005, The contagious leader: The impact of the leader's mood on the mood of group members, group affective tone, and group processes. Journal of Applied Psychology, 90,295-305.

[16] Stefanie K. Johnson. 2008 ' I second that emotion: Effects of emotional contagion and affect at work on leader and follower outcomes. The Leadership Quarterly 19,1-19.

[17] Topolinski, S., Likowski, K. U., Weyers, P., \& Strack, F. 2009.The face of fluency: Semantic coherence automatically elicits a specific pattern of facial muscle reactions. Cognition and Emotion, 23(2), 260-271.

[18] Van Kleef, G. A. 2009. How emotions regulate social life: The emotions as social information (EASI) model. Current Directions in Psychological Science, 18(3), 184-188.

[19] Volmer, J. 2012, Catching leaders' mood: Contagion effects in teams. Administrative Sciences, 2(3), 203-220.

[20] Waller, D J; Smith, S R; Warnock, J T 1989.Situational theory of leadership. American journal of hospital pharmacy, 46(11):23-41.

[21] Weiss, H. M., \& Cropanzano, R. 1996 Affective events theory: A theoretical discussion of the structure, causes and consequences of affective experiences at work. In B. M. Staw \& L. L. Cummings (Eds.), Research in organizational behavior: An annual series of analytical essays and critical reviews (vol. 18, pp. 1-74). US: Elsevier Science/JAI Press.

[22] Wong, C.S., Law, K.S. 2002. The Effects of Leader and Follower Emotional Intelligence on Performance and Attitude: An Exploratory Study. The Leadership Quarterly, (13): 243-274. 